Article

\title{
Voltammetric Determination of 5-Hydroxymethyl-2-furfural in Processed Cheese Using an Easy-Made and Economic Integrated 3D Graphene-like Electrode
}

\author{
Yuzhen Li ${ }^{1,+}+\mathbb{D}$, Juanhua Zhang ${ }^{2,+}$, Mengxiao Lv ${ }^{2}$, Yihui Bai ${ }^{2}$, Xuexiang Weng ${ }^{2}$, Chunping You ${ }^{1,3, *}$ \\ and Zhenmin Liu ${ }^{1,3}$ (D) \\ 1 State Key Laboratory of Dairy Biotechnology, Shanghai Engineering Research Center of Dairy Biotechnology, \\ Postdoctoral Workstation of Bright Dairy-Shanghai Jiao Tong University, Dairy Research Institute, \\ Bright Dairy \& Food Co., Ltd., Shanghai 200436, China; liyuzhen@brightdairy.com (Y.L.); \\ liuzhenmin@brightdairy.com (Z.L.) \\ 2 Key Laboratory of the Ministry of Education for Advanced Catalysis Materials, College of Chemistry and Life \\ Sciences, Zhejiang Normal University, Jinhua 321004, China; juanhuazhang2021@163.com (J.Z.); \\ lvmengxiao@zjnu.edu.cn (M.L.); baiyihui@zjnu.cn (Y.B.); xuexian@zjnu.cn (X.W.) \\ 3 Synergetic Innovation Center of Food Safety and Nutrition, Jiangnan University, Wuxi 214122, China \\ * Correspondence: youchunping@brightdairy.com \\ + These authors contributed equally to this work.
}

check for updates

Citation: Li, Y.; Zhang, J.; Lv, M.; Bai, Y.; Weng, X.; You, C.; Liu, Z. Voltammetric Determination of 5-Hydroxymethyl-2-furfural in Processed Cheese Using an Easy-Made and Economic Integrated 3D Graphene-like Electrode. Sensors 2022, 22, 64. https://doi.org/ $10.3390 /$ s22010064

Academic Editor: Cecilia Cristea

Received: 19 November 2021

Accepted: 19 December 2021

Published: 23 December 2021

Publisher's Note: MDPI stays neutral with regard to jurisdictional claims in published maps and institutional affiliations.

Copyright: (C) 2021 by the authors. Licensee MDPI, Basel, Switzerland. This article is an open access article distributed under the terms and conditions of the Creative Commons Attribution (CC BY) license (https:// creativecommons.org/licenses/by/ $4.0 /)$.

\begin{abstract}
The concentration of 5-hydroxymethyl-2-furfural (HMF) is an important quality-related index in milk and milk products. Fast, cost-effective and environmentally friendly determination of HMF is of great significance in milk products control. In this study, a three-dimensional (3D) graphenelike surface (3DGrls) was successfully prepared within $5 \mathrm{~min}$ by an electrochemical amperometric pretreatment on a pencil graphite electrode (PGE). The fast-obtained 3D graphene-like surface increased the electrode surface area and enhanced the electron transfer capability without the addition of any harmful chemicals. The morphology and chemical composition of the obtained electrode were characterized by scanning electron microscope (SEM), X-ray photoelectron spectroscopy (XPS), Raman spectroscopy and electrochemical impedance spectroscopy (EIS). The results found that the electrochemical response to HMF at the prepared 3DGrls/PGE was 34 times higher than that at PGE. The modified electrode showed a good linear response to HMF in a concentration range of $0.35 \sim 116 \mu \mathrm{M}$ with a low limit of detection (LOD) of $0.099 \mu \mathrm{M}$. The integrated electrode also exhibited excellent stability and wonderful antifouling property. Furthermore, the 3DGrls/PGE was successfully applied for the determination of HMF in three processed cheese samples with satisfactory results.
\end{abstract}

Keywords: 5-hydroxymethyl-2-furfural; pencil graphite electrode; three-dimensional graphene-like surface; sensor; processed cheese

\section{Introduction}

5-hydroxymethyl-2-furfural (HMF) is a furan derivative, mainly used as a renewable material and a versatile platform molecule. It is also widely used in medicine, chemical industry, pesticide and other fields [1]. HMF is also produced in foods (milk, cheese, meat, bread, etc.) during heat treatment and long-term storage [2-5]. Due to the abundant carbohydrates and proteins, four different furfural compounds (HMF, furfural, furylmethylcetone and methylfurfural) were mainly produced by Maillard reaction between reducing sugars and lysine-rich proteins in milk products (liquid milk, milk powder, cheese, etc.). The concentration of HMF was found to be much higher than the other three [6,7]. Therefore, the concentration of HMF is an important quality-related index in milk products. However, the human central nervous system, liver, kidney and heart will be damaged 
when the concentration of HMF exceeds a certain limit of the body absorption [8]. Therefore, it is very important to establish a convenient, reliable and efficient method for the fast determination of HMF in milk products.

The common detection method for HMF is chromatography, such as high-performance liquid chromatography (HPLC) [9-14], headspace gas chromatography [15] and gas chromatography coupled with triple quadrupole mass spectrometry (GC-MS/MS) [16]. In addition, UV-Vis spectrophotometric methods are also official methods for HMF determination in different matrices [17-19]. However, all of these methods have some drawbacks, such as expensive and sophisticated equipment, toxic reagents and heavy interfering effects. In contrast, the electrochemical method has the advantages of simple operation, easy portability, short analysis time and high sensitivity, which can overcome the aforementioned problems [20]. Nanomaterials, especially two-dimensional (2D)-layered nanomaterials, have been widely used in high-efficiency electrochemical sensors because of their large specific surface area, excellent adsorption capacity, superior electrochemical activity and excellent signal amplification performance [21-24]. However, there are few reports on the quantitative determination of HMF in real samples by the electrochemical method, especially based on electrodes modified with nanomaterials [25-29]. Very recently, we reported the successful determination of HMF in milk by a black phosphorene nanosheets (BP)-modified glassy carbon electrode (GCE) [30]. Although this electrochemical method is simple and sensitive, the drop-casting preparation of BP on GCE leads to instability of the sensing signal. How to realize the detection of HMF in dairy products more stably, quickly and environmentally friendly is still an urgent problem to be solved in the dairy industry.

Graphene, a 2D carbon nanomaterial with a $\mathrm{sp}^{2}$-hybridised honeycomb structure, is an ideal material for electrochemical sensors due to its large surface area and fast electron transfer ability [31-35]. Three-dimensional (3D) graphene is one of the derivatives of graphene, which not only possesses the intrinsic properties of graphene but also has an interconnected 3D conductive network and special microenvironment structure [36]. Due to its large surface area, good diffusion performance and high electric conductivities, 3D graphene synthesized from various strategies has attracted increasing attention in sensorrelated devices [37]. However, it has not been reported in HMF detection.

$\mathrm{Up}$ to now, the preparation methods of 3D graphene mainly include the electrochemical method [38], self-assembled method [39] and template-assisted method [40]. The main disadvantage of the electrochemical method is the uncontrollable morphology. The template-assisted chemical vapor deposition (CVD) method is commonly used to obtain 3D graphene with controllable morphology. However, many defects are generated during the process of removing the template, which affects the sensor performance [41]. The self-assembly method can realize the mass production of graphene with a low cost; however, its application is limited by defects such as a long preparation time, poor electrical conductivity and uncontrollable spatial network structure. The traditional fabrication of a 3D graphene-modified electrode usually involves first synthesizing the material offline and then immobilizing the material on the electrode surface using the drop-casting method. The two-step strategy has some problems, such as complicated synthesis and poor electrode response stability and reproducibility.

Recently, Parvez et al. [42] reported a method for electrochemically stripping graphite into graphene by applying a $+10-\mathrm{V}$ direct current $(\mathrm{DC})$ voltage to an inorganic salt electrolyte. Inspired by the above work and the existing achievements of our research group [43], herein, a 3D graphene-like surface (3DGrls) was formed within $300 \mathrm{~s}$ in a $\mathrm{Na}_{2} \mathrm{SO}_{4}$ solution using the in situ electrochemical expansion of a pencil graphite electrode (PGE) without anything hazardous added. The ultrafast-prepared electrode, namely, 3DGrls/PGE, not only has a larger surface area but also enhances the electron transfer ability. Under the optimized conditions, the 3DGrls/PGE was used for the determination of HMF by linear sweep voltammetry (LSV) with a low detection limit and a wide linear range. Moreover, the 3DGrls/PGE was successfully applied to the direct determination of HMF in processed cheese. 


\section{Materials and Methods}

\subsection{Chemicals and Reagents}

PGEs (2B, $0.5 \mathrm{~mm}$ in diameter) were purchased from Mitsubishi Pencil Company in Japan. Sodium sulfate (AR, $\geq 99 \%$, Sinopharm Chemical Reagent Co. Ltd., Shanghai, China)), disodium hydrogen phosphate (AR, $\geq 99 \%$, Sinopharm Chemical Reagent Co. Ltd., Shanghai, China), sodium dihydrogen phosphate (AR, $\geq 99 \%$, Sinopharm Chemical Reagent Co. Ltd., Shanghai, China), potassium ferricyanide (AR, $\geq 99 \%$, Sinopharm Chemical Reagent Co. Ltd., Shanghai, China), potassium ferrocyanide (AR, $\geq 99 \%$, Sinopharm Chemical Reagent Co. Ltd., Shanghai, China), potassium chloride (AR, $\geq 99 \%$, Sinopharm Chemical Reagent Co. Ltd., Shanghai, China, calcium chloride (AR, $\geq 93 \%$, Sinopharm Chemical Reagent Co. Ltd., Shanghai, China), zinc chloride (AR, $\geq 99 \%$, Sinopharm Chemical Reagent Co. Ltd., Shanghai, China), glucose (AR, $\geq 99 \%$, Sinopharm Chemical Reagent Co. Ltd., Shanghai, China) and oxalic acid (AR, $\geq 99.5 \%$, Sinopharm Chemical Reagent Co. Ltd., Shanghai, China) were used in the research..HMF (AR, $\geq 99 \%$, Aladdin Chemistry Co. Ltd., Shanghai, China), lactose (AR, $\geq 98 \%$, Aladdin Chemistry Co. Ltd., Shanghai, China), trichloroacetic acid (AR, $\geq 99 \%$, Aladdin Chemistry Co. Ltd., Shanghai, China), ascorbic acid (AR, $\geq 99.7 \%$, Aladdin Chemistry Co. Ltd., Shanghai, China) and L-lysine (AR, $\geq 99 \%$, Aladdin Chemistry Co. Ltd., Shanghai, China) were used directly after purchase without further purification. The 0.1-M phosphate buffer solutions (PBS) ( $\mathrm{pH}$ 9.18) were prepared by mixing $\mathrm{NaH}_{2} \mathrm{PO}_{4}$ and $\mathrm{Na}_{2} \mathrm{HPO}_{4}$ as the supporting electrolyte, and the $\mathrm{pH}$ was adjusted by $\mathrm{NaOH}$. The solution of HMF was prepared in PBS (pH 9.18) and kept away from light. Ultrapure fresh water used in all runs, with a resistivity of $18 \mathrm{M} \Omega$ $\mathrm{cm}$, was obtained from a Millipore water purification system (MilliQ, Molsheim, France).

\subsection{Apparatus}

All electrochemical measurements were performed using a CHI 660C electrochemical workstation (Chenhua Instrument Company, Shanghai, China) in a standard three-electrode cell system, consisting of a PGE or a modified PGE as the working electrode, a saturated calomel electrode (SCE) as the reference electrode and a platinum wire as the counter electrode. In the sensing of HMF, high-purity nitrogen gas was used to purify the solution for $10 \mathrm{~min}$ before running voltammetry experiments and was kept flowing above the solution to maintain the nonoxygen environments. EIS was obtained from the IM6E impedance measurement unit (Zahner, Germany). The $5-\mathrm{mM}\left[\mathrm{Fe}(\mathrm{CN})_{6}\right]^{3-/ 4-}$ solution containing $0.1-\mathrm{M} \mathrm{KCl}$ was supported at an open circuit potential with an amplitude of $50 \mathrm{mV}$ and a frequency range from $0.01 \mathrm{~Hz}$ to $100 \mathrm{kHz}$.

The morphology of the modified electrode was obtained from a Hitachi S- 4800 scanning electron microscopy (SEM; Tokyo, Japan). The composition evidence was further inferred by X-ray photoelectron spectroscopy (XPS) using a K-Alpha XPS spectrometer (SCIENTIFIC ESCALAB 250) with Al-K $\alpha$ X-ray radiation $(1486.6 \mathrm{eV})$ as the excitation source. The X-ray diffraction (XRD) analysis of Bruker D8 ADVANCE in Germany was carried out with a graphite monochromatized $\mathrm{Cu} \mathrm{K} \alpha$ radiation source $(\lambda=1.54056 \AA)$. Raman spectra were obtained by a He/Ne laser at $633 \mathrm{~nm}$ on the Renishaw RM1000 spectrometer.

\subsection{Fabrication of $3 D G r l s / P G E$}

The preparation of 3DGrls/PGE was based on our previous report [43]. In detail, the commercial PGE was sealed with $\mathrm{AB}$ glue in the middle, leaving the bottom end about $0.5-\mathrm{cm}$ exposed to obtain a fixed geometric area of the electrode surface (about $0.73 \mathrm{~cm}^{2}$ ). The PGE was electrolyzed in $0.1-\mathrm{M} \mathrm{Na}_{2} \mathrm{SO}_{4}$ solution at a constant potential of $3.0 \mathrm{~V}$ (vs. saturated calomel electrode, SCE) for $300 \mathrm{~s}$ to acquire a 3D graphene-like surface. Then, the resulting electrode (denoted as 3DGrls/PGE) was cleaned with deionized water and dried at room temperature for further characterization. 


\subsection{LSV Determination of Real Samples}

Three processed cheese samples were purchased from a local supermarket. A small amount $(0.50 \mathrm{~g})$ of crushed cheese was dispersed in $12 \mathrm{~mL}$ of water and sonicated for $30 \mathrm{~min}$. After shaking for $20 \mathrm{~min}$, the dispersion was heated in bath water $\left(100^{\circ} \mathrm{C}\right)$ for $25 \mathrm{~min}$ upon the addition of $5 \mathrm{~mL}$ of $0.15-\mathrm{M}$ fresh oxalic acid. The cooling solution was then pretreated according to our previous report $[44,45]$. For LSV determination, a certain volume of the pretreated sample was added into the electrochemical cell, and PBS (pH 9.18) was added to give a final 10-mL solution. The standard curve was further used to calculate the content of HMF, and the results were compared simultaneously with HPLC results.

\subsection{HPLC Determination of Real Samples}

The HMF was determined by RP-HPLC-DAD, with a slight modification of the AlbalaHurtado method [46]. The $0.05 \mathrm{~g}$ of crushed cheese was dispersed in $12 \mathrm{~mL}$ of water and treated with ultrasound for $30 \mathrm{~min}$. After shaking for $20 \mathrm{~min}$, the dispersion was then pretreated according to our previous report [6].

\section{Results and Discussion}

\subsection{Optimization of Preparation Conditions of $3 D G r l s / P G E$ \\ 3.1.1. Electrolyte Concentration}

In order to investigate the effect of the electrolyte concentration on the performance of the modified electrode, $\mathrm{Na}_{2} \mathrm{SO}_{4}$ electrolytes with three different concentrations of $1 \mathrm{M}, 0.1 \mathrm{M}$ and $0.01 \mathrm{M}$ were used to prepare 3DGrls/PGE. Figure $1 \mathrm{~A}$ shows the cyclic voltammograms (CV) curves of the 3DGrls/PGE electrodes in $10 \mathrm{~mL}$ of $0.1-\mathrm{M} \mathrm{KCl}$ containing a $5-\mathrm{mM}$ $\left[\mathrm{Fe}(\mathrm{CN})_{6}\right]^{3-/ 4-}$ solution. It can be seen that the peak current increases with the increase of the concentration of $\mathrm{Na}_{2} \mathrm{SO}_{4}$ from $0.01 \mathrm{M}$ to $0.1 \mathrm{M}$, indicating more ions available for graphite intercalation [42]. However, a decrease in the peak current can be observed when the concentration of $\mathrm{Na}_{2} \mathrm{SO}_{4}$ is as high as $1 \mathrm{M}$. A higher concentration of $\mathrm{Na}_{2} \mathrm{SO}_{4}$ means a lower amount of free water molecules left in the solution, resulting in a slower speed of water reduction at the cathode and insufficient hydroxyl ions $\left(\mathrm{OH}^{-}\right)$created. A lower concentration of $\mathrm{OH}^{-}$ions leads to less attacked edge sites and grain boundaries of graphite, which leads to less formation of interconnected 3D graphene-like surfaces. Thus, the electrodes used in the subsequent study were all pretreated in $0.1-\mathrm{M} \mathrm{Na}_{2} \mathrm{SO}_{4}$ electrolyte.

\subsubsection{Electrolysis Potential}

When a DC voltage is applied to the PGE electrode, the graphite layers of PGE will be expanded, and a spatial network of graphene will be created. Varied applied potentials lead to different degrees of a 3D-connected network of graphene and different electrochemical performances [43]. Figure $1 \mathrm{~B}$ shows the $\mathrm{CV}$ curves of the electrodes obtained with different voltages applied in $10 \mathrm{~mL}$ of $5-\mathrm{mM}\left[\mathrm{Fe}(\mathrm{CN})_{6}\right]^{3-/ 4-}$ solution. At a potential of $2 \mathrm{~V}$, only a sluggish $\mathrm{CV}$ peak of $\left[\mathrm{Fe}(\mathrm{CN})_{6}\right]^{3-/ 4-}$ with a big peak potential difference $\left(\Delta \mathrm{E}_{\mathrm{p}}\right)$ can be observed, suggesting the unsuccessful creation of a 3D network on the surface of PGE because of the low voltage. When the voltage is increased to $3 \mathrm{~V}$, the peak current dramatically increases. However, higher voltages result in a decrease in the peak current of $\left[\mathrm{Fe}(\mathrm{CN})_{6}\right]^{3-/ 4-}$, which may be attributed to the dissociation and dispersion of graphite flakes into the electrolyte solution. Therefore, $3 \mathrm{~V}$ is the best electrolysis potential for preparing 3DGrls/PGE.

\subsubsection{Electrolysis Time}

A varied electrolysis time will influence the electrochemical performance of the 3DGrls/PGE. A constant potential with time-varying electrolysis causes different degrees of graphite expansion and swelling, resulting in different surface areas, electrochemical conductivities and the mass transport of 3DGrls/PGE. As shown in Figure 1C, the highest CV response to $\left[\mathrm{Fe}(\mathrm{CN})_{6}\right]^{3-/ 4-}$ is achieved at $300 \mathrm{~s}$, and a longer time will decrease the current due to the overdissociation of graphite. Therefore, $300 \mathrm{~s}$ was selected for further studies. 

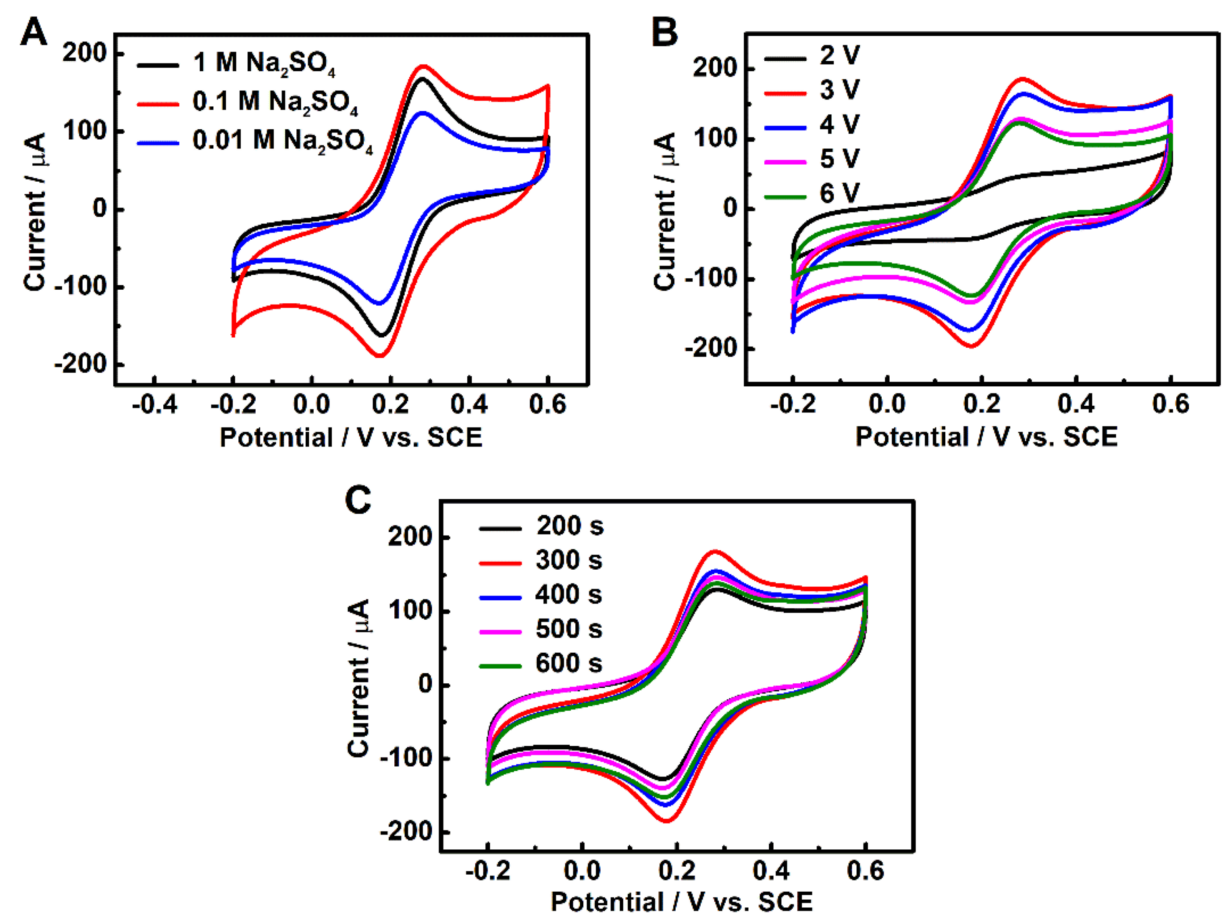

Figure 1. CV curves of 3DGrls/PGE prepared with different (A) electrolyte concentrations, (B) electrolysis potentials and $(\mathrm{C})$ electrolysis times in a $5-\mathrm{mM}\left[\mathrm{Fe}(\mathrm{CN})_{6}\right]^{3-/ 4-}$ solution at a scan rate of $50 \mathrm{mV} \mathrm{s}^{-1}$.

\subsection{Characterizations of $3 D G r l s / P G E$}

The surface morphologies, crystal structures and chemical compositions of PGE and 3DGrls/PGE were characterized by SEM, XRD, XPS and Raman. Figure 2A,B shows the SEM images of PGE and 3DGrls/PGE. After the short time of electrolysis, the interconnected 3D scaffold structure can be clearly observed for 3DGrls/PGE. This porous network facilitates the penetration of the target molecules and provides a large electrochemically active surface area.

The XRD patterns of PGE and 3DGrls/PGE in Figure 2C reveal that both of them have two sharp diffraction peaks at $26.5^{\circ}$ and $54.7^{\circ}$ corresponding to the crystal plane of graphite (002) and (004), indicating that the crystal configuration of graphite is not changed by the electrolysis for $300 \mathrm{~s}$ at $3 \mathrm{~V}$. The Raman spectra of PGE and 3DGrls/PGE in Figure 2D exhibit two characteristic peaks at $1331 \mathrm{~cm}^{-1}$ and $1572 \mathrm{~cm}^{-1}$ corresponding to the D-band and G-band of graphite. The $\mathrm{D} / \mathrm{G}\left(\mathrm{I}_{\mathrm{D}} / \mathrm{I}_{\mathrm{G}}\right)$ intensity ratio of Raman spectroscopy is often used to appraise the $\mathrm{sp}^{2}$ ring clusters in $\mathrm{sp}^{2}$ and $\mathrm{sp}^{3}$-bonded carbon networks [47]. The $\mathrm{I}_{\mathrm{D}} / \mathrm{I}_{\mathrm{G}}$ value increases observably from PGE (0.55) to 3DGrls/PGE (1.15), indicating an increased average size of $\mathrm{sp}^{3}$ and more structural defects in 3DGrls/PGE because of the opening of the graphite edge layer after the electrochemical oxidation of the PGE surface [48].

In the full XPS spectra of PGE and 3DGrls/PGE (Figure 2E), although the two peaks of carbon and oxygen are both presented, the $\mathrm{O} / \mathrm{C}$ ratio in 3DGrls/PGE is higher than that of PGE because of the electrolysis. The same results can be seen from the high-resolution C1s spectra (Figure 2F). Compared with the original PGE, 3DGrls/PGE demonstrates a much lower intensity of olefinic $\mathrm{sp}^{2}$ carbon, along with a higher oxygen content and $\mathrm{sp}^{3}$ hybrid carbon $(\mathrm{C}-\mathrm{O}, \mathrm{C}=\mathrm{O}, \mathrm{O}-\mathrm{C}=\mathrm{O})$ [49]. As shown in the high-resolution $\mathrm{O} 1 \mathrm{~s}$ spectra (Figure 2G), three higher peaks can be observed at 531.31, 532.5 and $533.1 \mathrm{eV}$, corresponding to the $\mathrm{O}-\mathrm{C}=\mathrm{O}, \mathrm{C}-\mathrm{O}-\mathrm{C}$ and $\mathrm{C}-\mathrm{OH}$ groups of 3DGrls/PGE, respectively [50]. These results indicate that part of olefinic $\mathrm{sp}^{2} \mathrm{C}$ of the original PGE is converted to $\mathrm{sp}^{3} \mathrm{C}$ due to doping $\mathrm{O}$ during the electrochemical expansion process, which is consistent with the results of Raman spectroscopy [51]. 

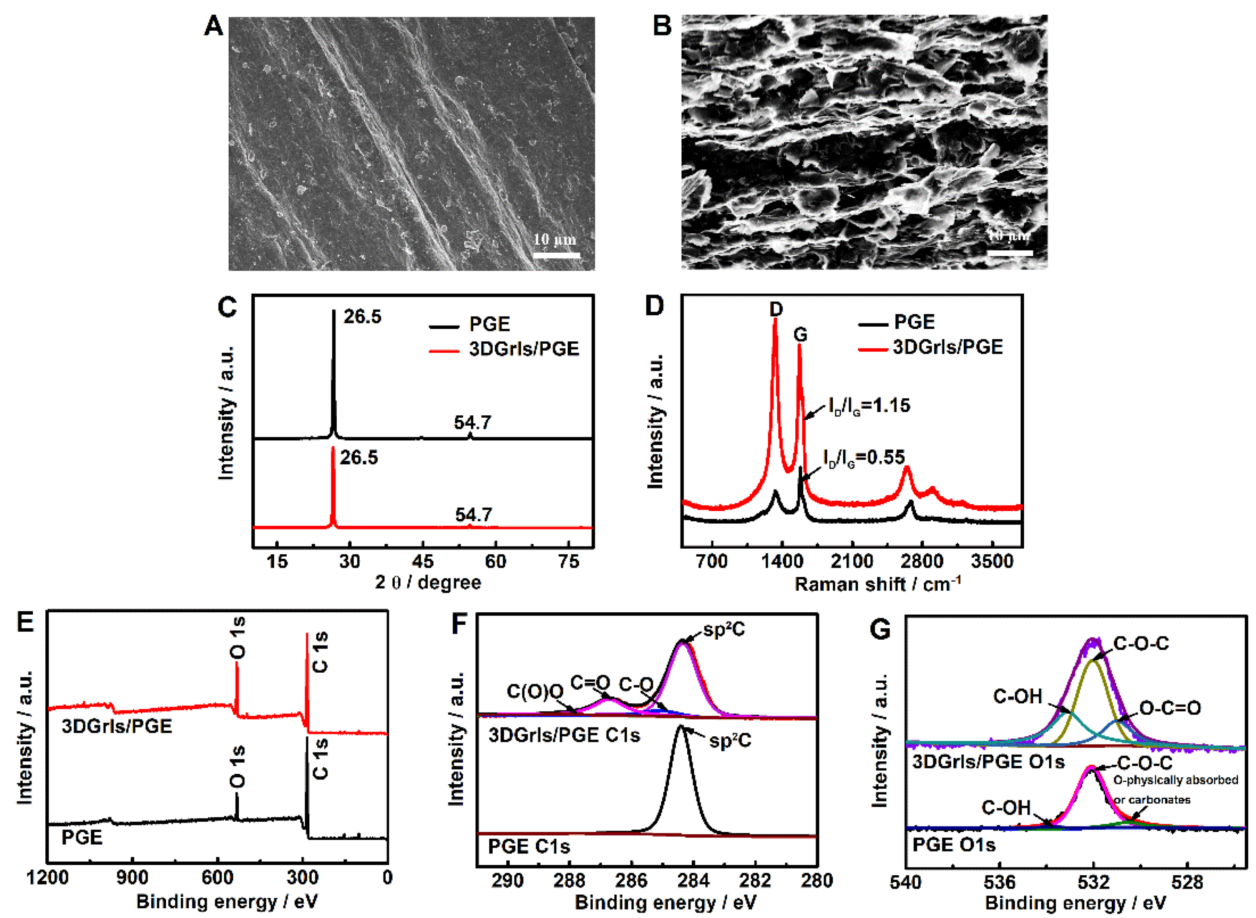

Figure 2. SEM images of (A) PGE and (B) 3DGrls/PGE. (C) XRD patterns and (D) Raman spectra of PGE and 3DGrls/PGE. (E) XPS full scan, (F) high-resolution C1 and (G) O1 spectra of PGE and 3DGrls/PGE.

\subsection{Electrochemical Behaviors of $3 D G r l s / P G E$}

To investigate the electrocatalytic behaviors of the 3DGrls/PGE, cyclic voltammograms were first performed in PBS and $\left[\mathrm{Fe}(\mathrm{CN})_{6}\right]^{3-/ 4-}$ solutions. Compared with PGE, the background current of 3DGrls/PGE in PBS is greatly increased (Figure 3A), indicating a higher capacitance current due to the large specific surface area and pore structure of the 3D graphene-like surface. When 3DGrls/PGE was immersed in the $\left[\mathrm{Fe}(\mathrm{CN})_{6}\right]^{3-/ 4-}$ solution, a pair of quasi-reversible redox peaks was observed (Figure 3B) with a smaller $\Delta E_{\mathrm{p}}$ of $200 \mathrm{mV}$, while that at PGE was $500 \mathrm{mV}$, indicating that the 3D graphene-like surface on 3DGrls/PGE can promote electron transfer between the probes and 3DGrls/PGE [52]. Moreover, the peak current at 3DGrls/PGE was larger than that at PGE, indicating that 3DGrls/PGE had a larger electroactive surface area, which was proved by the determination results of the electroactive surface area of 3DGrls/PGE $\left(3.04 \mathrm{~cm}^{2}\right)$ and PGE $\left(0.73 \mathrm{~cm}^{2}\right)$ (Figure 3C). The EIS of 3DGrls/PGE (Figure 3D) shows a straight line, while that of PGE displays a depressed semi-circle. The charge transfer resistance $\left(R_{\mathrm{ct}}\right)$ values of 3DGrls/PGE and PGE calculated from the equivalent circuit inset in Figure $3 \mathrm{D}$ are 363 and $4837 \Omega$, respectively. The dramatically decreased $R_{\mathrm{ct}}$ of 3DGrls/PGE exhibits lower electron transfer resistance and a greater electron transfer rate. The electrochemical behaviors of 3DGrls/PGE indicate that the 3D graphene-like surface formed on PGE within $5 \mathrm{~min}$ after constant electrochemical oxidation not only increases the specific surface area of the electrode but also accelerates the electron transfer rate. 
A
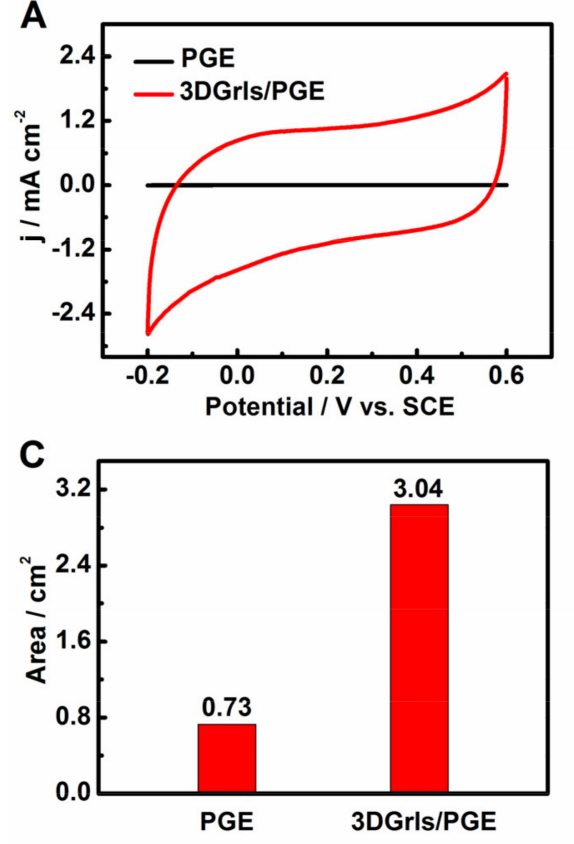

B

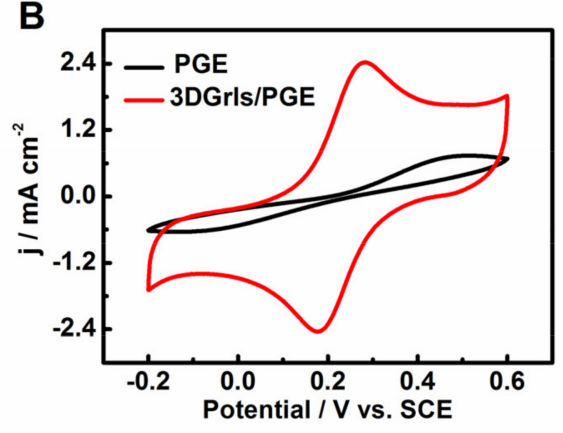

D

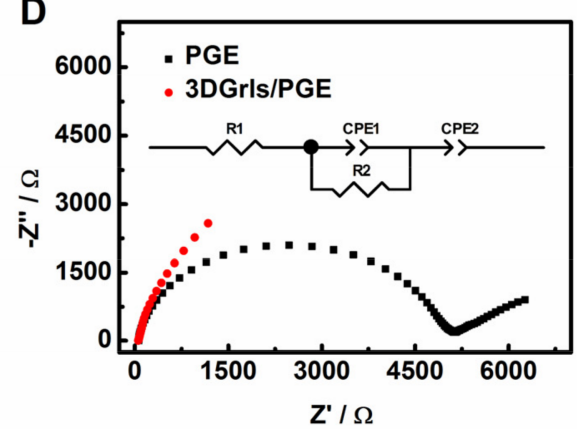

Figure 3. The CV curves of PGE and 3DGrls/PGE in (A) pH 9.18 PBS and (B) 0.1-M KCl solution containing $5-\mathrm{mM}\left[\mathrm{Fe}(\mathrm{CN})_{6}\right]^{3-/ 4-}$ at a scan rate of $50 \mathrm{mV} \mathrm{s}^{-1}$. (C) The corresponding area histogram of PGE and 3DGrls/PGE. (D) The EIS of PGE and 3DGrls/PGE with the voltage amplitude at $50 \mathrm{mV}$ in the frequency range $10^{-2}-10^{5} \mathrm{~Hz}$. The inset shows the respective equivalent circuit diagram, where $R_{1}, R_{2}$ and CPE represent the solution resistance, charge transfer resistance and constant phase elements, respectively.

\subsection{Electrochemical Reduction of HMF at 3DGrls/PGE}

The voltammetric performances of PGE and 3DGrls/PGE were further checked in PBS (pH 9.18) containing 0.5-mM HMF using CV and LSV with the curves shown in Figure 4. A reduction peak is presented at about $-1.35 \mathrm{~V}$, but no oxidation peak is observed for both $\mathrm{CV}$ curves (Figure $4 \mathrm{~A}$ ) in the potential range from -1.6 to $-1.2 \mathrm{~V}$, suggesting the irreversible electrochemical reduction of HMF at different electrodes. The reduction peak current $\left(I_{p}, c\right)$ of HMF at 3DGrls/PGE is 34 times that at PGE. A similar electrocatalytic activity for HMF is also found in the LSV results (Figure 4B), with a larger peak current (18 times higher) and a smaller (positive shift of $24 \mathrm{mV}$ ) overpotential at 3DGrls/PGE compared with that at PGE, indicating that 3DGrls/PGE has a better electrocatalytic activity for HMF reduction.
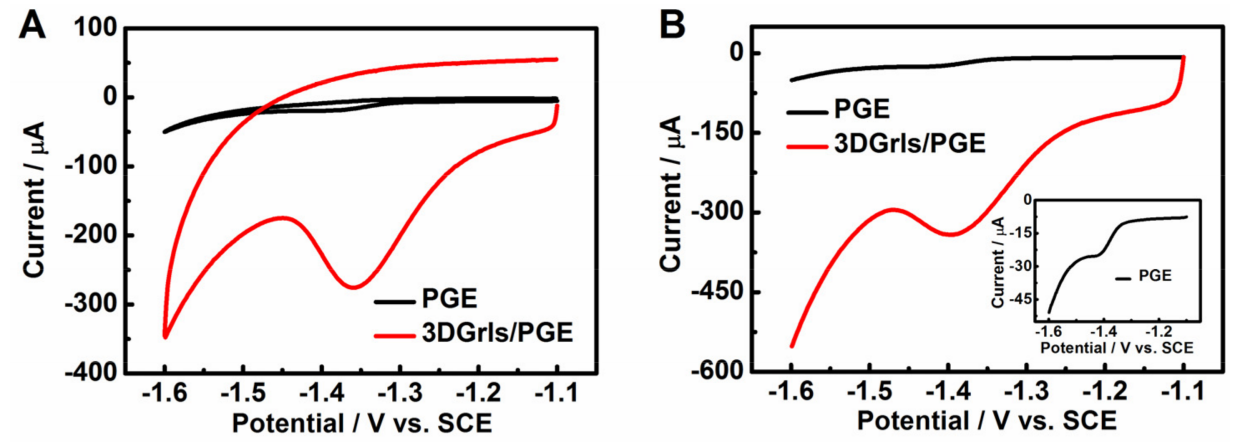

Figure 4. (A) CV and (B) LSV curves of PGE and 3DGrls/PGE in pH 9.18 PBS with 20- $\mu$ M HMF. The inset is the LSV at PGE. Scan rate: $50 \mathrm{mV} \mathrm{s}^{-1}$.

\subsection{Effect of Scan Rate}

The cyclic voltammograms of HMF corresponding to various scan rates for the 3DGrls/PGE were investigated. As shown in Figure 5, the reduction peak current of 
HMF increases with the increase of the scan rate and is linear with the square root of the scan rate in the range of $10 \sim 500 \mathrm{mV} \mathrm{s}^{-1}$, while the reduction peak potential shifts negatively (Figure 5A). The regression equation between the $I_{\mathrm{p}, \mathrm{c}}$ and the square root of the scan rate is as follows (Figure $5 \mathrm{~B}): I_{\mathrm{p}}=79.31-1109 v^{1 / 2}\left(\mathrm{R}^{2}=0.9919\right)$, indicating a typical diffusion-controlled electrochemical process involving two electrons and two protons (Scheme 1) [30].
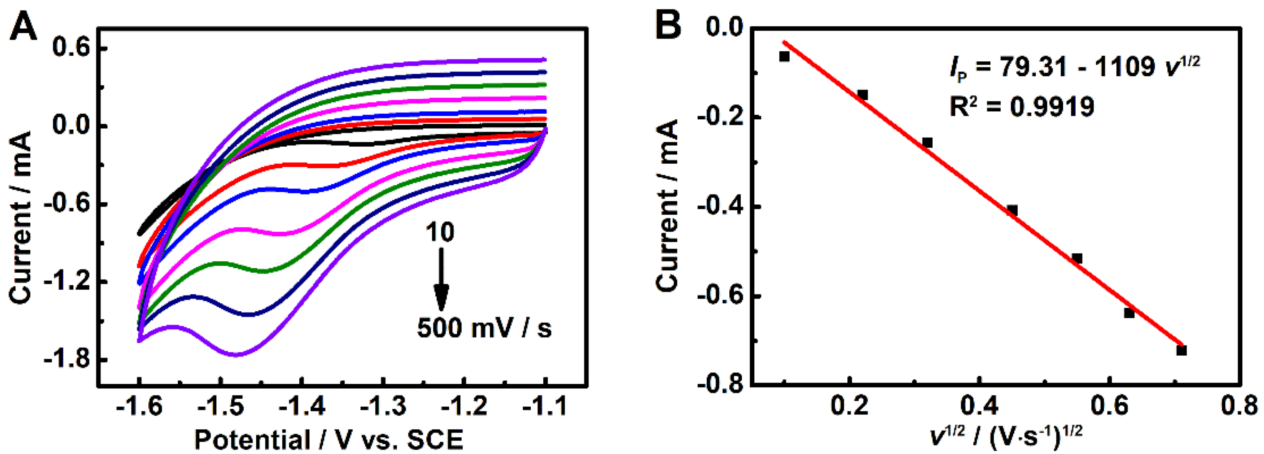

Figure 5. (A) CVs of 50- $\mu \mathrm{M}$ HMF in $\mathrm{pH} 9.18$ PBS solution with scan rates from 10 to $500 \mathrm{mV} \mathrm{s}^{-1}$. (B) The linear relationship between the reduction peak current $\left(I_{\mathrm{p}, \mathrm{c}}\right)$ of HMF and the square root of the scan rate $\left(v^{1 / 2}\right)$.<smiles>O=CC1=CC=C(CO)C1</smiles>

Scheme 1. The electroreduction mechanism of HMF.

\subsection{Determination of HMF}

Figure 6A shows the LSV responses with different concentrations of HMF. As shown, the reduction peak current of HMF increases with the successive injection of HMF and displays a good linearity from 0.35 to $116 \mu \mathrm{M}$ (Figure 6B), with a detection limit of $0.099 \mu \mathrm{M}$ $(0.012 \mu \mathrm{g} / \mathrm{mL}, \mathrm{S} / \mathrm{N}=3)$ following the linear regression equation $I_{\mathrm{p}}=-0.00471 c-0.0286$ $\left(\mathrm{R}^{2}=0.990\right)$. The performance of 3DGrls/PGE was also compared with other modified electrodes, and the results are shown in Table 1. The 3DGrls/PGE with a wide linear range and a low detection limit can be used for the electrochemical quantitative determination of HMF in real samples.
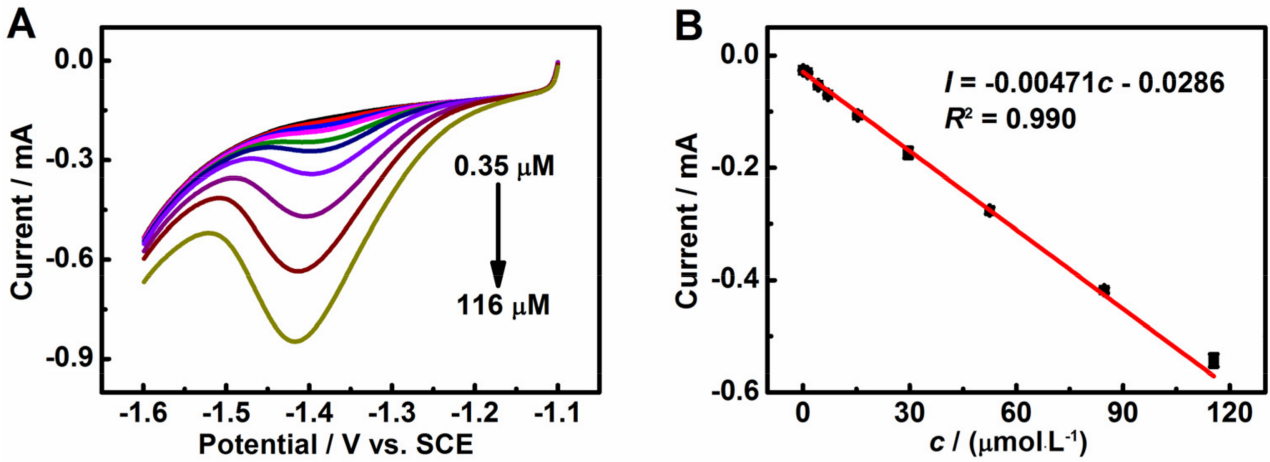

Figure 6. (A) LSV profiles at 3DGrls/PGE in pH 9.18 PBS containing different concentrations of HMF from 0.35 to $116 \mu \mathrm{M}$. (B) The relationship between the reduction peak current and HMF concentration. Scan rate: $100 \mathrm{mV} \mathrm{s}^{-1}$. 
Table 1. Comparisons of the sensing performances of different electrodes for the determination of HMF.

\begin{tabular}{|c|c|c|c|c|c|}
\hline Technique & Electrode & Real Sample & $\begin{array}{c}\text { Linear Range } \\
(\mu \mathrm{g} / \mathrm{mL})\end{array}$ & $\operatorname{LOD}(\mu \mathrm{g} / \mathrm{mL})$ & Ref. \\
\hline SWV a & $\mathrm{SMDE}^{\mathrm{d}}$ & $\begin{array}{l}\text { pharmaceutical and } \\
\text { food }\end{array}$ & - & 0.01 & [25] \\
\hline DPV & $\mathrm{MDE}^{\mathrm{e}}$ & honey & - & 0.048 & [26] \\
\hline $\mathrm{PAD}^{\mathrm{b}}$ & NiNPs/GCE ${ }^{f}$ & sugarcane bagasse & $0.1-1.26$ & 0.054 & [27] \\
\hline $\mathrm{CV}$ and SWV & GCE & honey & $\begin{array}{c}0.15-1.26(\mathrm{CV}) \\
0.03-0.38 \text { (SWV) }\end{array}$ & $\begin{array}{c}0.0833(\mathrm{CV}) \\
0.0072 \text { (SWV) }\end{array}$ & [28] \\
\hline LSV and CA ${ }^{c}$ & $\mathrm{Cu}-\mathrm{Ni} \mathrm{MP} / \mathrm{CuE} \mathrm{g}$ & food & $\begin{array}{c}50.44-1261.10 \text { (LSV) } \\
0.05-1387.21 \text { (CA) }\end{array}$ & $\begin{array}{l}0.443 \text { (LSV) } \\
0.005 \text { (CA) }\end{array}$ & [29] \\
\hline DPV & BP-GCE $^{h}$ & milk & $0.1-10$ & 0.012 & [30] \\
\hline LSV & 3DGrls/PGE & processed cheese & $0.044-14.63$ & 0.012 & This work \\
\hline
\end{tabular}

\subsection{Repeatability, Reproducibility, Stability and Selectivity of 3DGrls/PGE}

The repeatability of the 3DGrls/PGE for the voltammetric response of 50- $\mu \mathrm{M}$ HMF was investigated by 100 successive measurements. It can be seen from Figure 7A that the corresponding reduction peak current of the 100 th $\mathrm{CV}$ scan can still retain $78.7 \%$ of the original value, indicating that the 3DGrls/PGE has an excellent repeatability.
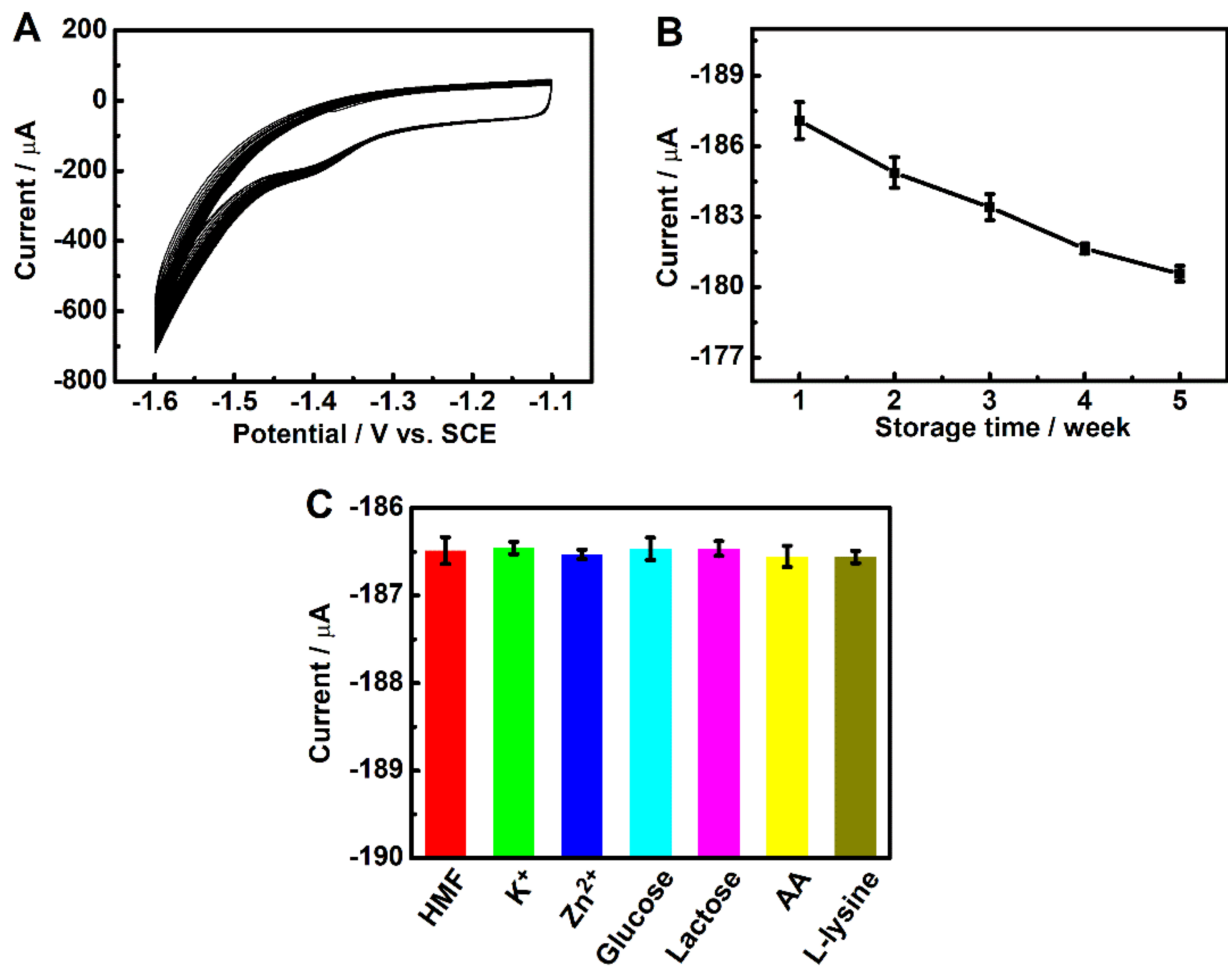

Figure 7. (A) CV curves of 100 consecutive scans of 50- $\mu \mathrm{M}$ HMF in $\mathrm{pH} 9.18$ PBS solution at 3DGrls/PGE, and (B) the current responses after storage in a refrigerator for 1, 2, 3, 4 and 5 weeks. Scan rate: $50 \mathrm{mV} \mathrm{s}^{-1}$. (C) The reduction peak current in the presence of interfering substances.

The reproducibility of the 3DGrls/PGE for the determination of 50- $\mu \mathrm{M} \mathrm{HMF}$ in a $\mathrm{pH}$ 9.18 PBS was measured at three different parallel electrodes under the same conditions, respectively. The reduction peak currents of all the electrodes were almost the same, with 
a small relative standard deviation (RSD) of 4.5\%, suggesting the 3DGrls/PGE has good reproducibility.

The long-term storage stability of 3DGrls/PGE was also evaluated by storing the same electrode for 5 weeks in a refrigerator. The corresponding reduction peak current after 5 weeks retained $96.3 \%$ of the original value, indicating that the 3DGrls/PGE with excellent storage stability can be used to detect HMF in real samples.

To evaluate the specificity of 3DGrls/PGE, possible interferences for the determination of 50- $\mu \mathrm{M}$ HMF in PBS ( $\mathrm{pH}$ 9.18) were investigated by adding possible interferences into the processed cheese sample. It can be seen from Figure 7C that the concentrations of 100 times of $\mathrm{K}^{+}$and $\mathrm{Zn}^{2+}$ and 50 times of lactose, glucose, L-lysine and AA cannot affect the determination of HMF with less than $6 \%$ change in the reduction peak current, indicating that 3DGrls/PGE has a wonderful anti-interference ability.

\subsection{Real Sample Analysis}

To evaluate the feasibility and validity of 3DGrls/PGE, the HMF amounts in three processed cheese samples were directly detected and compared with the HPLC results. As shown in Table 2, the developed method fits quite well with the HPLC method, indicating that the developed ultra-fast electrode is feasible for the determination of HMF in real samples.

Table 2. Determination of HMF in real samples with the 3DGrls/PGE $(n=5)$.

\begin{tabular}{ccccc}
\hline \multirow{2}{*}{ Sample } & \multicolumn{2}{c}{ 3DGrls/PGE } & \multicolumn{2}{c}{ HPLC } \\
\cline { 2 - 5 } & HMF $(\mu \mathrm{g} / \mathbf{g})$ & RSD $(\%)$ & HMF $(\mu \mathrm{g} / \mathbf{g})$ & RSD $(\%)$ \\
\hline Processed cheese A & 86.84 & 5.2 & 83.55 & 2.1 \\
\hline Processed cheese B & 82.01 & 2.9 & 80.66 & 1.8 \\
\hline Processed cheese C & 75.37 & 3.9 & 76.88 & 1.5 \\
\hline
\end{tabular}

\section{Conclusions}

A low-cost and pollution-free HMF-sensitive sensor was developed by applying constant potential oxidation on the PGE surface for $5 \mathrm{~min}$. The obtained surface of the electrode is similar to 3D graphene. The thin graphene sheets are connected in space, and the electrode has a large specific surface area and a fast electron transfer rate. The results showed that the integrated 3DGrls/PGE has a good electrochemical response to HMF under optimal conditions. The linear range is wide $(0.35 \sim 116 \mu \mathrm{M})$, and the detection limit is as low as $0.099 \mu \mathrm{M}(\mathrm{S} / \mathrm{N}=3)$. More importantly, the 3DGrls/PGE can be applied to determine the HMF in several processed cheese samples, and the results matched well with the HPLC results. The electrode preparation method proposed herein has the following advantages: (1) Simple and fast. A 3D graphene-like electrode surface can be generated in 300 s. (2) Green and friendly. No environmentally unfriendly reagents are required during the preparation process. (3) Good stability. The integrated electrode avoids the electrode material falling off the electrode surface and greatly improves the stability of the sensor.

Author Contributions: Conceptualization, Y.L. and J.Z.; methodology, X.W., C.Y. and Y.L.; validation, C.Y. and Z.L.; formal analysis, Y.L. and J.Z.; investigation, J.Z.; resources, M.L. and Y.B.; data curation, Y.L. and J.Z. writing_original draft preparation, Y.L.; writing—review and editing, X.W. and C.Y.; visualization, J.Z. and M.L.; supervision, X.W.; project administration, Z.L. and funding acquisition, X.W. and C.Y. All authors have read and agreed to the published version of the manuscript.

Funding: This research was funded by the National Key R\&D Program of China (2017YFC1600404), the Shanghai Engineering Research Center of Dairy Biotechnology (19DZ2281400), the Open Project Program of State Key Laboratory of Dairy Biotechnology (SKLDB2019-003) and the Zhejiang Provincial Natural Science Foundation of China (LY20B020006).

Institutional Review Board Statement: Not applicable. 


\section{Informed Consent Statement: Not applicable.}

Data Availability Statement: The data is contained within the article.

Conflicts of Interest: The authors declare no conflict of interest.

\section{References}

1. Kowalski, S.; Lukasiewicz, M.; Duda-Chodak, A.; Zięć, G. 5-Hydroxymethyl-2-furfural (HMF)-heat-induced formation, occurrence in food and biotransformation-A review. Pol. J. Food Nutr. Sci. 2013, 63, 207-225. [CrossRef]

2. Capuano, E.; Fogliano, V. Acrylamide and 5-Hydroxymethylfurfural (HMF): A review on metabolism, toxicity, occurrence in food and mitigation strategies. LWT Food Sci. Technol. 2011, 44, 793-810. [CrossRef]

3. de Andrade, J.K.; de Andrade, C.K.; Komatsu, E.; Perreault, H.; Torres, Y.R.; da Rosa, M.R.; Felsner, M.L. A validated fast difference spectrophotometric method for 5-hydroxymethyl-2-furfural (HMF) determination in corn syrups. Food Chem. 2017, 228, 197-203. [CrossRef] [PubMed]

4. Teixidó, E.; Santos, F.; Puignou, L.; Galceran, M. Analysis of 5-hydroxymethylfurfural in foods by gas chromatography-mass spectrometry. J. Chromatogr. A 2006, 1135, 85-90. [CrossRef] [PubMed]

5. Murkovic, M.; Bornik, M.-A. Formation of 5-hydroxymethyl-2-furfural (HMF) and 5-hydroxymethyl-2-furoic acid during roasting of coffee. Mol. Nutr. Food Res. 2007, 51, 390-394. [CrossRef]

6. Xing, Q.; Ma, Y.; Fu, X.; Cao, Q.; Zhang, Y.; You, C. Effects of heat treatment, homogenization pressure, and overprocessing on the content of furfural compounds in liquid milk. J. Sci. Food Agric. 2020, 100, 5276-5282. [CrossRef] [PubMed]

7. Xing, Q.; Fu, X.; Liu, Z.; Cao, Q.; You, C. Contents and evolution of potential furfural compounds in milk-based formula, ultra-high temperature milk and pasteurised yoghurt. Int. Dairy J. 2021, 120, 105086. [CrossRef]

8. Li, H.; Chen, X.; Ren, J.; Deng, H.; Peng, F.; Sun, R. Functional relationship of furfural yields and the hemicellulose-derived sugars in the hydrolysates from corncob by microwave-assisted hydrothermal pretreatment. Biotechnol. Biofuels 2015, 8, 127. [CrossRef]

9. de Andrade, J.K.; Komatsu, E.; Perreault, H.; Torres, Y.R.; da Rosa, M.R.; Felsner, M.L. In house validation from direct determination of 5-hydroxymethyl-2-furfural (HMF) in brazilian corn and cane syrups samples by HPLC-UV. Food Chem. 2016, 190, 481-486. [CrossRef]

10. Vecová, B.; Mach, M. Content of 5-hydroxymethyl-2-furfural in biscuits for kids. Interdiscip. Toxicol. 2017, 10, 66-69. [CrossRef]

11. Barrera, J.; Pedreschi, F.; Gómez, J.P.; Zúñiga, R.N.; Mariotti-Celis, M.S. In house validation for the direct determination of 5-hydroxymethyl-2-furfural (HMF) in "Dulce de Leche". J. Food Compos. Anal. 2020, 95, 103665. [CrossRef]

12. Nemitz, M.C.; Picada, J.N.; da Silva, J.; Garcia, A.L.H.; Papke, D.K.; Grivicich, I.; Steppe, M.; von Poser, G.L.; Teixeira, H.F Determination of the main impurities formed after acid hydrolysis of soybean extracts and the in vitro mutagenicity and genotoxicity studies of 5-ethoxymethyl-2-furfural. J. Pharm. Biomed. Anal. 2016, 129, 427-432. [CrossRef]

13. Durmaz, G.; Gökmen, V. Determination of 5-hydroxymethyl-2-furfural and 2-furfural in oils as indicators of heat pre-treatment. Food Chem. 2010, 123, 912-916. [CrossRef]

14. Margarita, D.; Yovcho, K.; Desislava, K.; Stoilova, A. Alidation of HPLC method for analysis of 5-hydroxymethyl-2-furfural in tobacco smoke. Comptes Rendus De L Academie Bulgare Des Sci. 2020, 73, 1531-1537.

15. Hu, H.-C.; Zhang, Y.; Zeng, T.; Zhou, W.; Chen, L.; Huang, L.; Ni, Y. Determination of cellulose derived 5-hydroxymethyl2-furfural content in lignocellulosic biomass hydrolysate by headspace gas chromatography. Cellulose 2018, 25, 3843-3851. [CrossRef]

16. Shen, Z.; Ma, X.; Ali, M.M.; Liang, J.; Du, Z. Analysis of the evolution of potential and free furfural compounds in the production chain of infant formula and risk assessment. Food Chem. 2021, 368, 130814. [CrossRef] [PubMed]

17. Truzzi, C.; Annibaldi, A.; Illuminati, S.; Finale, C.; Rossetti, M.; Scarponi, G. Determination of very low levels of 5-(hydroxymethyl)2-furaldehyde (hmf) in natural honey: Comparison between the HPLC technique and the spectrophotometric white method. $J$. Food Sci. 2012, 77, C784-C790. [CrossRef] [PubMed]

18. Zappalà, M.; Fallico, B.; Arena, E.; Verzera, A. Methods for the determination of hmf in honey: A comparison. Food Control 2005, 16, 273-277. [CrossRef]

19. Gürkan, R.; Altunay, N. Quantification of 5-hydroxymethylfurfural in honey samples and acidic beverages using spectrophotometry coupled with ultrasonic-assisted cloud point extraction. J. Food Compos. Anal. 2015, 42, 141-151. [CrossRef]

20. Kimmel, D.W.; Leblanc, G.; Meschievitz, M.E.; Cliffel, D.E. Electrochemical sensors and biosensors. Anal. Chem. 2012, 84, 685-707.

21. Agüí, L.; Yáñez-Sedeño, P.; Pingarrón, J.M. Role of carbon nanotubes in electroanalytical chemistry: A review. Anal. Chim. Acta 2008, 622, 11-47. [CrossRef]

22. Su, S.; Chao, J.; Pan, D.; Wang, L.; Fan, C. Electrochemical sensors using two-dimensional layered nanomaterials. Electroanalysis 2015, 27, 1062-1072. [CrossRef]

23. Yang, G.; Zhu, C.; Du, D.; Zhu, J.; Lin, Y. Graphene-like two-dimensional layered nanomaterials: Applications in biosensors and nanomedicine. Nanoscale 2015, 7, 14217-14231. [CrossRef]

24. Zhu, C.; Yang, G.; Li, H.; Du, D.; Lin, Y. Electrochemical sensors and biosensors based on nanomaterials and nanostructures. Anal. Chem. 2014, 87, 230-249. [CrossRef] [PubMed] 
25. Shamsipur, M.; Beigi, A.A.; Teymouri, M.; Tash, S.A.; Samimi, V. Electrocatalytic application of girard's reagent $\mathrm{t}$ to simultaneous determination of furadehydes in pharmaceutical and food matrices by highly sensitive voltammetric methods. Electroanalysis 2010, 22, 1314-1322. [CrossRef]

26. Reyes-Salas, E.O.; Manzanilla-Cano, J.A.; Barceló-Quintal, M.H.; Juárez-Mendoza, D.; Reyes-Salas, M. Direct electrochemical determination of hydroxymethylfurfural (HMF) and its application to honey samples. Anal. Lett. 2006, 39, 161-171. [CrossRef]

27. Da Silva, J.L.; Beluomini, M.A.; Stradiotto, N.R. Determination of furanic aldehydes in sugarcane bagasse by high-performance liquid chromatography with pulsed amperometric detection using a modified electrode with nickel nanoparticles. J. Sep. Sci. 2015, 38, 3176-3182. [CrossRef]

28. Salhi, I.; Samet, Y.; Trabelsi, M. Direct electrochemical determination of very low levels of 5-hydroxymethyl furfural in natural honey by cyclic and square wave voltammetric techinques. J. Electroanal. Chem. 2020, 873, 114326. [CrossRef]

29. Ye, Y.; Zhang, H.; Kahaljan, G.; Wang, M.; Mohet, A.; He, S.; Cao, X.; Zheng, H. Electro-oxidation and determination 5hydaoxymethylfurfural in food on co-electrodeposited $\mathrm{Cu}-\mathrm{Ni}$ bimetallic microparticles modified copper electrode. Food Chem. 2022, 367, 130659. [CrossRef]

30. Li, Y.; Huang, L.; Weng, X.; Liu, Z.; You, C. Black phosphorene modified electrochemical sensor for fast determination of 5-hydroxymethyl-2-furfural in milk. Electroanalysis 2021, 33, 2452-2459. [CrossRef]

31. Rao, C.N.R.; Gopalakrishnan, K.; Maitra, U. Comparative study of potential applications of graphene, MoS2, and other twodimensional materials in energy devices, sensors, and related areas. ACS Appl. Mater. Interfaces 2015, 7, 7809-7832. [CrossRef]

32. Zhao, Y.; Li, X.-G.; Zhou, X.; Zhang, Y.-N. Review on the graphene based optical fiber chemical and biological sensors. Sens. Actuators B Chem. 2016, 231, 324-340. [CrossRef]

33. Song, Y.; Luo, Y.; Zhu, C.; Li, H.; Du, D.; Lin, Y. Recent advances in electrochemical biosensors based on graphene two-dimensional nanomaterials. Biosens. Bioelectron. 2016, 76, 195-212. [CrossRef]

34. Sattar, T. Current review on synthesis, composites and multifunctional properties of graphene. Top. Curr. Chem. 2019, $377,10$.

35. Nag, A.; Mitra, A.; Mukhopadhyay, S. Graphene and its sensor-based applications: A review. Sens. Actuators A Phys. 2018, 270, 177-194. [CrossRef]

36. Xu, Y.; Shi, G.; Duan, X. Self-assembled three-dimensional graphene macrostructures: Synthesis and applications in supercapacitors. Acc. Chem. Res. 2015, 48, 1666-1675. [CrossRef]

37. Baig, N.; Saleh, T.A. Electrodes modified with 3D graphene composites: A review on methods for preparation, properties and sensing applications. Microchim. Acta 2018, 185, 283. [CrossRef] [PubMed]

38. Yang, S.; Lohe, M.R.; Müllen, K.; Feng, X. New-generation graphene from electrochemical approaches: Production and applications. Adv. Mater. 2016, 28, 6213-6221. [CrossRef] [PubMed]

39. Lv, W.; Tao, Y.; Ni, W.; Zhou, Z.; Su, F.-Y.; Chen, X.-C.; Jin, F.-M.; Yang, Q.-H. One-Pot Self-Assembly of Three-Dimensional Graphene Macroassemblies with Porous Core and Layered Shell. J. Mater. Chem. 2011, 21, 12352-12357. [CrossRef]

40. Chen, Z.; Ren, W.; Gao, L.; Liu, B.; Pei, S.; Cheng, H.-M. Three-Dimensional Flexible and Conductive Interconnected Graphene Networks Grown by Chemical Vapour Deposition. Nat. Mater. 2011, 10, 424-428.

41. Chen, Z.; Jin, L.; Hao, W.; Ren, W.; Cheng, H.-M. Synthesis and applications of three-dimensional graphene network structures Mater. Today Nano 2019, 5, 100027. [CrossRef]

42. Parvez, K.; Wu, Z.-S.; Li, R.; Liu, X.; Graf, R.; Feng, X.; Müllen, K. Exfoliation of graphite into graphene in aqueous solutions of inorganic salts. J. Am. Chem. Soc. 2014, 136, 6083-6091. [CrossRef]

43. Xiang, X.; Feng, S.; Chen, J.; Feng, J.; Hou, Y.; Ruan, Y.; Weng, X.; Milcovich, G. Gold nanoparticles/electrochemically expanded graphite composite: A bifunctional platform toward glucose sensing and SERS applications. J. Electroanal. Chem. 2019, 851, 113471. [CrossRef]

44. Boekel, M.; Zia-Ur-Rehman. Determination of HMF in heated milk by HPLC. Milk Dairy 1987, 41, $297-306$.

45. Wang, Q.; Zhang, J.; Xu, Y.; Wang, Y.; Wu, L.; Weng, X.; You, C.; Feng, J. A one-step electrochemically reduced graphene oxide based sensor for sensitive voltammetric determination of furfural in milk Products. Anal. Methods 2020, 13, 56-63. [CrossRef]

46. Albalá-Hurtado, S.; Veciana-Nogués, M.T.; Izquierdo-Pulido, A.M.; Vidal-Carou, M.C. Determination of free and total furfural compounds in infant milk formulas by high-performance liquid chromatography. J. Agric. Food Chem. 1997, 45, 2128-2133. [CrossRef]

47. Bulmer, J.S.; Mizen, J.E.; Gspann, T.S.; Kaniyoor, A.; Ryley, J.B.; Kiley, P.J.; Sparkes, M.R.; O’Neill, B.; Elliott, J.A. Extreme stretching of high G:D ratio carbon nanotube fibers using super-acid. Carbon 2019, 153, 725-736. [CrossRef]

48. Shi, P.; Wang, Y.; Liang, X.; Sun, Y.; Cheng, S.; Chen, C.; Xiang, H. Simultaneously exfoliated boron-doped graphene sheets to encapsulate sulfur for applications in lithium-sulfur batteries. ACS Sustain. Chem. Eng. 2018, 6, 9661-9670. [CrossRef]

49. Beamson, G.; Briggs, D. High resolution XPS of organic polymers: The scienta ESCA 300 database biomaterials. Biomaterials 1994, $15,318-321$.

50. Ondřej, J.; Michal, N.; Jan, L.; David, S.; Marie, B.; Martin, P.; Zdeněk, S. Concentration of nitric acid strongly influences chemical composition of graphite oxide. Chem.-A Eur. J. 2017, 23, 6432-6440.

51. Li, L.; Wang, M.; Guo, J.; Cao, M.; Qiu, H.; Dai, L.; Yang, Z. Regulation of radicals from electrochemical exfoliation of a double-graphite electrode to fabricate high-quality graphene. J. Mater. Chem. C 2018, 6, 6257-6263. [CrossRef]

52. Bard, A.J.; Faulkner, L.R. Electrochemical Methods: Fundamentals and Applications, 2nd ed.; John Wiley \& Sons, Inc.: Hoboken, NJ, USA, 2000; pp. 157-161. 